\title{
Reconstitución inmune exitosa mediante trasplante de células madre hematopoyéticas en un paciente colombiano afectado con enfermedad granulomatosa crónica
}

\author{
Yermis Carolina Rocha', Juan Álvaro López ${ }^{1,2}$, Julio César Orrego', Yadira Coll13,4, \\ Amado Karduss $^{3}$, Sergio Rosenzweig ${ }^{5}$, José Luis Franco ${ }^{1}$ \\ 1 Grupo de Inmunodeficiencias Primarias, Facultad de Medicina, Universidad de Antioquia, Medellín, Colombia \\ 2 Escuela de Microbiología, Universidad de Antioquia, Medellín, Colombia \\ 3 Unidad de Trasplante Hematopoyético, Instituto de Cancerología, Clínica Las Américas, Medellín, Colombia \\ 4 Departamento de Pediatría y Puericultura, Facultad de Medicina, Universidad de Antioquia, Medellín, Colombia \\ 5 Infectious Diseases Susceptibility Unit, NIAID, National Institutes of Health, Bethesda, MD, USA
}

Introducción. La enfermedad granulomatosa crónica es una inmunodeficiencia primaria causada por mutaciones en los genes que codifican para las proteínas del sistema de la oxidasa de NADPH (Nicotinamide Adenine Dinucleotide Phosphate) de las células fagocíticas, las cuales afectan la producción de especies reactivas del oxígeno y la actividad microbicida. Actualmente, la única terapia curativa para esta enfermedad es la reconstitución inmune mediante el trasplante de células madre hematopoyéticas.

Objetivo. Reportar la caracterización clínica y molecular de un paciente con enfermedad granulomatosa crónica ligada al cromosoma $X$ y su reconstitución inmunitaria exitosa mediante el trasplante de células madre hematopoyéticas.

Materiales y métodos. El estallido respiratorio en neutrófilos de sangre periférica se midió por citometría de flujo mediante la prueba de oxidación de la dihidrorrodamina 123 (DHR 123). El análisis de las mutaciones del gen $C Y B B$ se hizo mediante reacción en cadena de la polimerasa (PCR) en el ADN complementario y la secuenciación e hibridación genómica comparativa en el ADN genómico. En el trasplante se emplearon células madre del hermano menor con HLA idéntico, y previamente se hizo un acondicionamiento de intensidad reducida. La reconstitución inmunitaria después del trasplante se evaluó periódicamente con hemoleucogramas y la prueba DHR 123 en neutrófilos de sangre periférica.

Resultados. El diagnóstico de la enfermedad granulomatosa crónica ligada al cromosoma $X$ se estableció como resultado de una deleción hemicigota en la banda Xp21.1 que implicó la deleción completa del CYBB. La toma de injerto postrasplante para plaquetas y neutrófilos fue en los días 10 y 11, respectivamente. En el día 30 después del trasplante se logró la reconstitución hematológica completa y en los tres años siguientes no se observaron complicaciones ni infecciones.

Conclusión. El trasplante de células madre hematopoyéticas permite la reconstitución completa de la función inmunitaria relacionada con la actividad microbicida de las células fagocíticas de pacientes con enfermedad granulomatosa crónica ligada al cromosoma X.

Palabras clave: enfermedad granulomatosa crónica, neutrófilos, NADPH oxidasa, especies reactivas del oxígeno, trasplante de células madre hematopoyéticas, acondicionamiento pretrasplante.

doi: http://dx.doi.org/10.7705/biomedica.v36i2.2870

Successful immune reconstitution by means of hematopoietic stem cell transplantation in a Colombian patient with chronic granulomatous disease

Introduction: Chronic granulomatous disease is a primary immunodeficiency that results from mutations in proteins of the NADPH oxidase system that affect the microbicidal activity of phagocytes. Immune reconstitution by hematopoietic stem cell transplantation is currently the only curative therapy for this disease.

\footnotetext{
Contribución de los autores:

Yermis Carolina Rocha: revisión de las historias clínicas del paciente, recolección de datos y redacción del manuscrito Juan Álvaro López: PCR del gen CYBB y diagnóstico molecular

Julio César Orrego: evaluación clínica y seguimiento del paciente

José Luis Franco: evaluación clínica, seguimiento del paciente, organización y redacción del manuscrito

Yadira Coll y Amado Karduss: trasplante de células madre hematopoyéticas

Sergio Rosenzweig: secuenciación del gen CYBB
} 
Objective: To describe the clinical and molecular characterization of a patient with X-linked chronic granulomatous disease and the successful immune reconstitution by means of a hematopoietic stem cell transplantation.

Methods: The respiratory burst was measured by flow cytometry using the dihydrorodamine 123 (DHR) oxidation test in neutrophils of peripheral blood. Mutational analysis of CYBB was performed by PCR amplification in complementary DNA, as well as sequencing and comparative genomic hybridization in genomic DNA. HLA-identical stem cells from the patient's younger brother were used for the transplantation and reduced intensity pre-transplantation conditioning was administered. Posttransplantation immune reconstitution was evaluated periodically by serial complete blood counts and DHR 123 in peripheral blood neutrophils.

Results: The diagnosis of $X$-linked chronic granulomatous disease resulted from a hemizygous deletion affecting Xp21.1 that included the entire CYBB. Post-transplantation engraftment was documented in platelets and peripheral blood neutrophils at days 10 and 11 , respectively. Total hematological reconstitution was achieved by day 30 post-transplantation and no complications or infections have been observed in the three years since the transplantation.

Conclusion: Hemopoietic stem cell transplantation allows for total reconstitution of the immune function related to microbicidal activity of phagocytic cells from patients with X-linked chronic granulomatous disease.

Key words: Granulomatous disease, chronic; neutrophils, NADPH oxidase, reactive oxygen species, hematopoietic stem cell transplantation, transplantation conditioning.

doi: http://dx.doi.org/10.7705/biomedica.v36i2.2870

La enfermedad granulomatosa crónica (EGC, Online Mendelian Inheritance in Man - OMIM \# 306400) es una inmunodeficiencia primaria producto de defectos genéticos que afectan el sistema de la oxidasa del fosfato dinucleótido de adenina de la nicotinamida (Nicotinamide Adenine Dinucleotide Phosphate, NADPH), el cual está encargado de la producción de especies reactivas del oxígeno para la actividad microbicida de las células fagocíticas $(1,2)$. Esta enfermedad tiene una prevalencia estimada de uno por 200.000 nacidos vivos y hasta $70 \%$ de los casos se deben a mutaciones ligadas al cromosoma $X$ en el gen que codifica para la proteína gp91 ${ }^{\text {phox }}(C Y B B)$, mientras que las formas autosómicas recesivas se deben a mutaciones en los genes que codifican para las proteínas $p 67^{\text {phox }}$, p22 ${ }^{\text {phox }}, \mathrm{p} 47^{\text {phox }}$ o p40 ${ }^{\text {phox }}(3-6)$.

Los pacientes con enfermedad granulomatosa crónica presentan infecciones recurrentes graves que afectan principalmente la piel, las vías respiratorias, el intestino, los ganglios linfáticos y, con menor frecuencia, órganos como el hígado, el bazo, el cerebro y los huesos, debidas principalmente a Staphylococcus aureus, Burkholderia cepacia, Serratia marcescens, Nocardia spp. y Aspergillus

\footnotetext{
Correspondencia:

José Luis Franco, Sede de Investigación Universitaria, Universidad de Antioquia, Calle $62 \mathrm{~N}^{\circ}$ 52-59, laboratorio 530, Medellín, Colombia

Teléfono: (574) 219 6472; fax: (574) 2191065

jose.franco@udea.edu.co

Recibido: 18/06/15; aceptado: 09/09/15
}

spp. (3-5,7). El manejo convencional de la enfermedad incluye el tratamiento agresivo de las enfermedades infecciosas con antimicrobianos y ciclos cortos de esteroides, y la profilaxis con antimicrobianos para bacterias y hongos, así como con interferón gamma recombinante humano (rhIFN- $\gamma$ ). No obstante, las infecciones graves siguen presentándose con una alta tasa de morbilidad y una mortalidad anual que fluctúa entre 2 y $5 \%(4,5,8,9)$. Además, los pacientes con esta enfermedad parecen tener un mayor riesgo de desarrollar infecciones y morir que los que presentan las formas autosómicas (6). No obstante, Kuhns, et al., demostraron que la supervivencia de los pacientes con la enfermedad está fuertemente asociada con la producción residual de los intermediarios reactivos del oxígeno, independientemente del gen afectado (10).

El trasplante de células madre hematopoyéticas como forma de lograr la reconstitución inmunitaria en las inmunodeficiencias primarias, fue reportado por primera vez en $1968(11,12)$. Hoy en día, los avances tecnológicos como la tipificación del HLA en alta resolución, el uso de células madre hematopoyéticas movilizadas en sangre periférica o en sangre de cordón umbilical, así como los tratamientos menos tóxicos de acondicionamiento y de profilaxis óptima para evitar la enfermedad de injerto contra huésped, lo han convertido en la mejor alternativa de reconstitución inmunitaria definitiva para muchos pacientes con diversas inmunodeficiencias primarias, lo cual mejora su 
supervivencia y calidad de vida (13-15). El trasplante de células madre hematopoyéticas en la enfermedad granulomatosa crónica es la única alternativa disponible actualmente para la curación de la enfermedad, con una supervivencia que oscila entre 90 y $95 \%$, incluso cuando se tiene un donante no emparentado $(3,5,9,15,16)$. Para los casos en que no hay un donante compatible, se viene evaluando experimentalmente la terapia génica como opción terapéutica $(1,6)$.

El presente artículo describe el caso de un paciente con enfermedad granulomatosa crónica ligada al cromosoma $X$ tratado exitosamente con el trasplante de células madre hematopoyéticas para la reconstitución de la función inmunitaria, en lo que constituye la primera experiencia exitosa en este campo en Colombia.

\section{Materiales y métodos}

\section{Aspectos éticos}

Se revisó la historia clínica y los exámenes de laboratorio del paciente y se obtuvieron muestras de sangre total de él, de sus familiares y de controles sanos que aceptaron participar voluntariamente en el estudio y firmaron el consentimiento informado, de acuerdo con las recomendaciones de la Declaración de Helsinki, el informe de Belmont y la Resolución 8430 de 1993 del Ministerio de Salud, título II, artículo 11.

\section{Evaluación del estallido respiratorio de neutrófilos}

Para el diagnóstico inicial de la enfermedad en el paciente recién nacido, se determinó el estallido respiratorio en neutrófilos mediante el examen con nitroazul de tetrazolio (NAT) en placa y siguiendo el procedimiento previamente descrito $(17,18)$. Posteriormente, se usó la técnica de oxidación de la DHR 123 (19), para lo cual se obtuvieron $4 \mathrm{ml}$ de sangre anticoagulada con heparina del paciente, la madre y un control sano, se incubaron en un volumen de $400 \mu \mathrm{l}$ con solución de lisis de glóbulos rojos $(8,3 \mathrm{mg} / \mathrm{ml}$ de cloruro de amonio, $0,84 \mathrm{mg} / \mathrm{ml}$ de bicarbonato de sodio y $0,5 \mathrm{M}$ de EDTA) a $37^{\circ} \mathrm{C}$ durante 5 minutos.

Después de la incubación, se lavaron las células con solución tampón HBSS (GIBCO, Grand Island, NY) y al botón resultante se le agregaron $400 \mu \mathrm{l}$ de solución tampón HBSS con suplemento de 3,6 $\mu \mathrm{l}$ de DHR $29 \mathrm{mM}$ (Invitrogen, Eugene, OR) y $10 \mu \mathrm{l}$ de solución de catalasa $(5 \mu \mathrm{g} / \mathrm{ml}$, Sigma, St. Louis, MO), y se incubó nuevamente a $37^{\circ} \mathrm{C}$ durante 5 minutos. Para la activación de los neutrófilos se usaron $10 \mu \mathrm{l}$ de una solución de PMA de $5 \mu \mathrm{g} / \mathrm{ml}$ (Sigma) y se incubó nuevamente a $37^{\circ} \mathrm{C}$ durante 14 minutos. La fluorescencia generada por la oxidación de la DHR 123 se determinó en un citómetro de flujo FACSCanto (Becton Dickinson, BD, San José, CA).

\section{Análisis de mutaciones del gen CYBB}

Para el análisis de mutaciones del gen $C Y B B$, se aplicó inicialmente una estrategia basada en la amplificación mediante reacción en cadena de la polimerasa (PCR) de tres segmentos que comprenden el ADN complementario (ADNc) del gen y que, además, facilitan la detección de defectos en el procesamiento alternativo (20).

Brevemente, se obtuvo ARN total de las células mononucleares de sangre periférica mediante el método de TRIzol (Invitrogen) y se hizo la transcripción inversa para generar ADNc empleando el kit ThermoScriptTM RT-PCR System (Invitrogen). Los fragmentos obtenidos se amplificaron mediante PCR empleando tres pares de cebadores que flanquean los 13 exones del CYBB, con el fin de obtener tres fragmentos correspondientes a los exones 1-5 (450 pb), 3-9 (700 pb) y 7-13 (900 pb). Los productos obtenidos se separaron en un gel de agarosa al 1,5 \% en solución tampón TBE 1X (trisborato-EDTA), que luego fue teñido con bromuro de etidio para la visualización de las bandas correspondientes.

Además, se obtuvo ADN genómico (ADNg) a partir de células mononucleares de sangre periférica mediante el método de salting out; se hizo su secuenciación y la de los fragmentos obtenidos a partir de la amplificación del ADNg, empleando cebadores específicos para todos los exones y segmentos correspondientes con el método de Sanger (National Institutes of Health, USA). Por último, se hizo la hibridación genómica comparativa basada en matrices (HGC), mediante la cual el ADNg del paciente y de un control sano marcan diferentes sondas fluorescentes y se colocan sobre una matriz con cebadores que amplifican todos los exones del CYBB. La hibridación de las muestras permite detectar la ganancia o pérdida de material genético (GeneDx, Gaithersburg, MD).

\section{Protocolo del trasplante de células madre hematopoyéticas}

El esquema de acondicionamiento de intensidad reducida previo al trasplante, consistió en fludaribina (180 mg/m², dosis total), ciclofosfamida (120 
$\mathrm{mg} / \mathrm{kg}$, dosis total), timoglobulina (5 $\mathrm{mg} / \mathrm{kg}$, dosis total) y radioterapia corporal total (300 cGy). La profilaxis para la enfermedad de injerto contra huésped se hizo con ciclosporina $A$ en dosis de $5 \mathrm{mg} / \mathrm{kg} / \mathrm{día}$, la cual se ajustó para mantener sus niveles plasmáticos entre 200 y $400 \mathrm{ng} / \mathrm{ml}$ hasta el día 180 después del trasplante. Además, se administró un curso corto con metotrexato en dosis de $5 \mathrm{mg} / \mathrm{m}^{2}$ por día (en los días 1, 3, 6 y 11 despues del trasplante). Por último, el paciente recibió profilaxis antibacteriana, antifúngica y antiviral con levofloxacina, fluconazol y aciclovir en las dosis estándar, y semanalmente se determinó la antigenemia para citomegalovirus.

Para el trasplante de células madre hematopoyéticas, el paciente recibió 5,25 × $10^{6}$ células CD34+ por $\mathrm{kg}$ de un total de $3,5 \times 10^{8}$ células nucleadas por $\mathrm{kg}$ procedentes de médula ósea, previamente movilizadas a sangre periférica mediante un tratamiento con filgrastim (10 mg/kg por día) durante tres días. El tiempo de la toma del injerto para los neutrófilos se definió como el primero de tres días consecutivos con un conteo de más de 500 neutrófilos/ $\mu \mathrm{l}$, y para las plaquetas, como el primero de tres días consecutivos con un conteo de 20.000 plaquetas/ul o más, sin necesidad de transfusión. El paciente se monitorizó en varios momentos con el fin de evaluar el funcionamiento del injerto y la producción de especies reactivas del oxígeno en los neutrófilos mediante el ensayo de DHR 123.

\section{Resultados \\ Caso clínico}

El paciente es un niño afrodescendiente de 11 años de edad, nacido en Medellín, Colombia, y producto del segundo embarazo a término de padres no consanguíneos. En los antecedentes familiares se documentó la muerte de su hermano mayor debido a sepsis neonatal por Enterobacter cloacae a los 12 días de nacido y de dos primos a los 2 y 30 meses de edad, respectivamente, a causa de múltiples infecciones recurrentes (figura 1, IV:2, IV:5 y IV:6).

Ante la sospecha de segregación de enfermedad granulomatosa crónica ligada al cromosoma $X$ en la familia, se evaluó el estallido respiratorio en neutrófilos de sangre periférica mediante examen de NAT y DHR 123 en la madre del paciente, la tía (madre de los dos primos fallecidos) y la abuela materna. En todos los casos se observó un patrón de 'mosaicismo', con lo cual se determinó que las tres eran portadoras de la enfermedad (no se presentan los datos), y se decidió hacer las pruebas de NAT y DHR 123 en el paciente inmediatamente después del nacimiento. Los resultados demostraron el defecto completo en el estallido respiratorio y, en consecuencia, se confirmó el diagnóstico de enfermedad granulomatosa crónica ligada al cromosoma X (figura $2 a$ y b).

Después del diagnóstico posnatal se inició la profilaxis antibacteriana y antifúngica, así como la administración de rhIFN- $\gamma\left(50 \mu \mathrm{g} / \mathrm{m}^{2}\right.$, tres veces a la semana). A pesar de esto, el paciente presentó varias enfermedades infecciosas graves que incluyeron: linfadenitis bacteriana por B. cepacia (a los 7 meses), bacteriemia por Salmonella spp. y adenitis regional por Mycobacterium bovis (a los 58 meses), así como varios abscesos perianales y, a los 7 años, meningitis y sepsis de posible origen gastrointestinal. Aunque en todos los casos recibió tratamientos antimicrobianos apropiados que resultaron en el control y la remisión de sus infecciones, dada su gravedad se planteó hacer el trasplante de células madre hematopoyéticas.

\section{Análisis de mutaciones del CYBB}

El análisis de mutaciones del $C Y B B$ se hizo con la PCR de tres segmentos a partir del ADNc, pero no se obtuvo amplificación (figura 3a), por lo cual se secuenció el gen a partir del ADNg con resultados similares (no se presentan los datos). Por último, se hizo hibridación genómica comparativa en el $A D N g$, la cual confirmó una deleción completa del $C Y B B$ (figura $3 b$ ).

\section{Trasplante de células madre hematopoyéticas en el paciente}

El trasplante de células madre hematopoyéticas finalmente se pudo hacer cuando el paciente tenía 8 años de edad, empleando células madre hematopoyéticas de su hermano menor. La tipificación del HLA en el paciente mediante PCR con iniciadores de secuencia específica (SequenceSpecific Primed PCR, PCR-SSP) empleando el estuche comercial del CTS (Collaborative Transplant Study, Heidelberg, Germany), reveló el siguiente resultado para el HLA:A*24,31, $B^{\star} 18,39, \mathrm{DRB} 1^{*} 08,15$ $\mathrm{DQB}^{\star}$ 04:02, 06:02, idéntico genéticamente al del donante, y del mismo grupo sanguíneo (B/Rh+).

La toma del injerto para neutrófilos se registró en el día 11 y el de plaquetas en el día 10, después del trasplante, con un conteo de 700 neutrófilos/ $\mu \mathrm{l}$ y 51.000 plaquetas $/ \mu \mathrm{l}$, respectivamente. En el día 30 después del trasplante se estableció la reconstitución hematológica completa y en el día 34 después del trasplante se hizo la prueba 


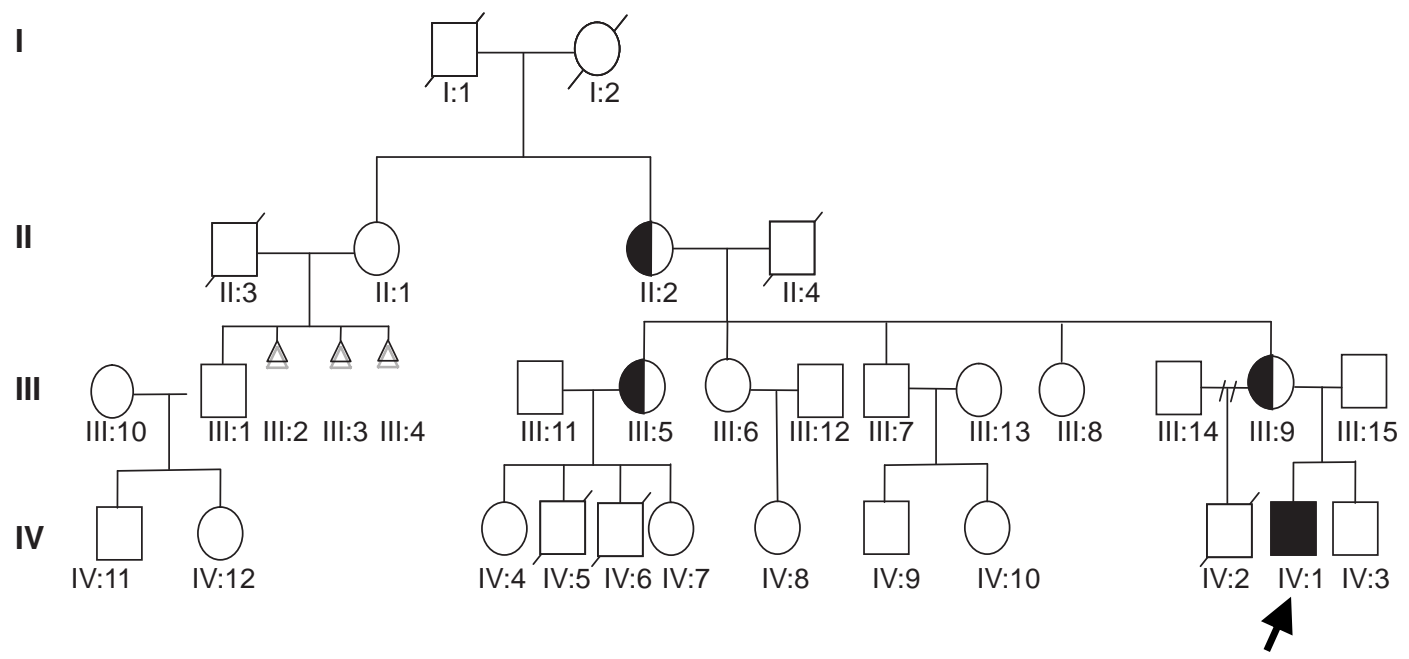

Figura 1. Genograma del paciente con enfermedad granulomatosa crónica ligada al cromosoma X. En esta genealogía se identifican las tres mujeres portadoras de la enfermedad, las cuales fueron diagnosticadas antes del nacimiento del niño del caso índice. También se identifican los dos primos y el hermano del paciente que murieron a temprana edad.

a)

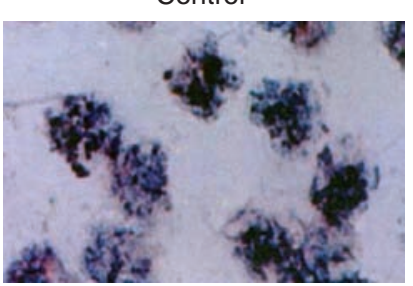

b)
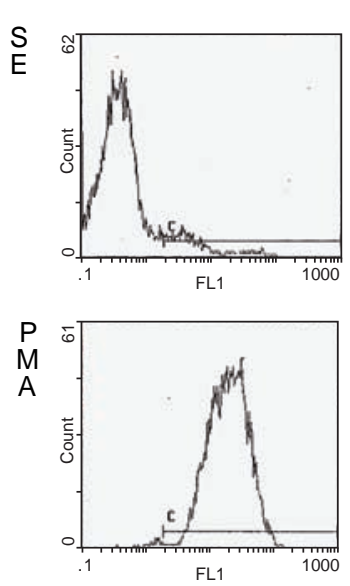

Madre

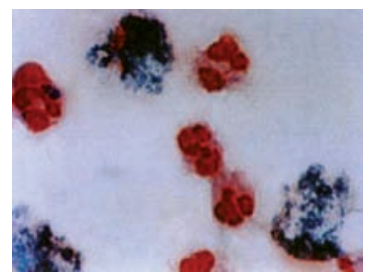

Madre
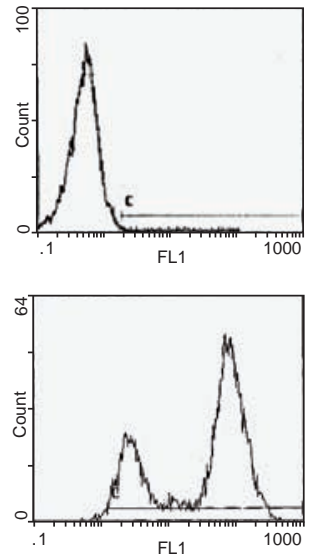

Paciente

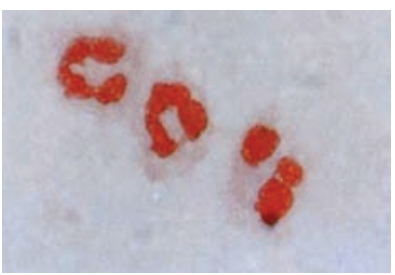

Paciente
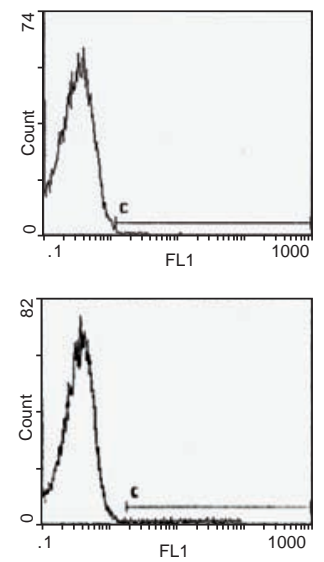

Figura 2. Diagnóstico bioquímico de un paciente con enfermedad granulomatosa crónica. a) Reducción del nitroazul de tetrazolio (NAT): las células del paciente no presentaban precipitados de formazán, por lo que no hubo reducción del NAT mientras que la madre presentó 'mosaicismo'. b) Citometría de flujo mediante DHR 123: después de la estimulación con PMA los neutrófilos del paciente no produjeron especies reactivas del oxígeno, mientras que en la madre se evidenciaron dos poblaciones: una que oxidaba la DHR 123 y otra que no lo hacía.

de DHR 123 en la cual se observó que más del $95 \%$ de los neutrófilos de sangre periférica habían producido peróxido de hidrógeno, el cual oxidó la DHR 123 (figura $4 a$ y c). Además, las mediciones seriadas sucesivas de DHR 123 en los neutrófilos del paciente hasta el día 442 después del trasplante, mostraron que más del $89 \%$ de sus células producían especies reactivas del oxígeno 
a) Exones 1-5

Exones 3-9

123 123

Exones 7-13
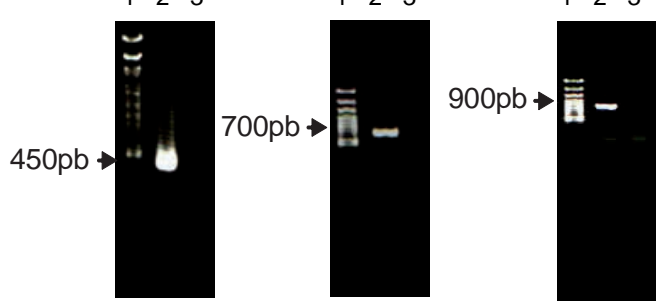

b)

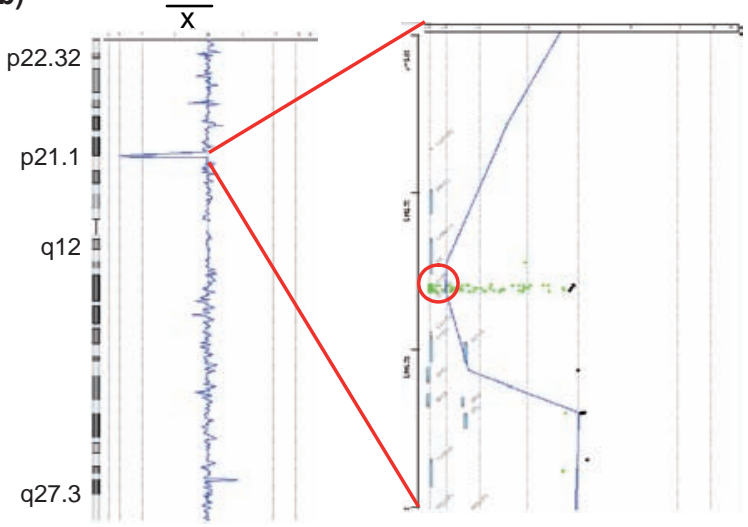

Figura 3. Análisis de mutaciones del gen $C Y B B$. a) Electroforesis en gel de agarosa para los productos obtenidos de la amplificación de los exones 1-5 (450 pb), de los exones 3-9 (700 pb) y de los exones 7-13 (900 pb) a partir del ADN complementario. Línea $1=100$ pb. Línea $2=$ control sano. Línea 3 = paciente. b) Representación gráfica del resultado de la hibridación genómica comparativa en el ADN genómico que muestra el área correspondiente a la deleción en Xp21.1. En la gráfica de la izquierda se muestra una representación del cromosoma X; la caída en la intensidad de la señal corresponde a una deleción localizada en la posición p21.1. La gráfica de la derecha es una amplificación de la posición p21.1. Los valores negativos (puntos verdes, paciente), corresponden a la pérdida de todos los exones del $C Y B B$.

tras la estimulación, lo cual evidenciaba el grado de quimerismo posterior al trasplante (figura $4 b$ ). Con base en los resultados de la DHR y lo reportado en la literatura científica, se consideró innecesario determinar el quimerismo a nivel genómico en el paciente (21).

A los cinco meses del trasplante, el paciente presentó candidiasis oral, única manifestación clínica después de este, la cual se trató adecuadamente con nistatina oral. Durante este lapso no hubo reactivación de la infección por citomegalovirus ni enfermedad de injerto contra huésped.

A los 16 meses del trasplante se reinició el esquema de vacunación para hepatitis $A$, hepatitis B, Haemophilus influenzae, tétanos, difteria y Streptococcus pneumoniae.

\section{Discusión}

La enfermedad granulomatosa crónica es una inmunodeficiencia primaria que resulta en una mayor propensión a presentar enfermedades infecciosas de forma recurrente, que a menudo

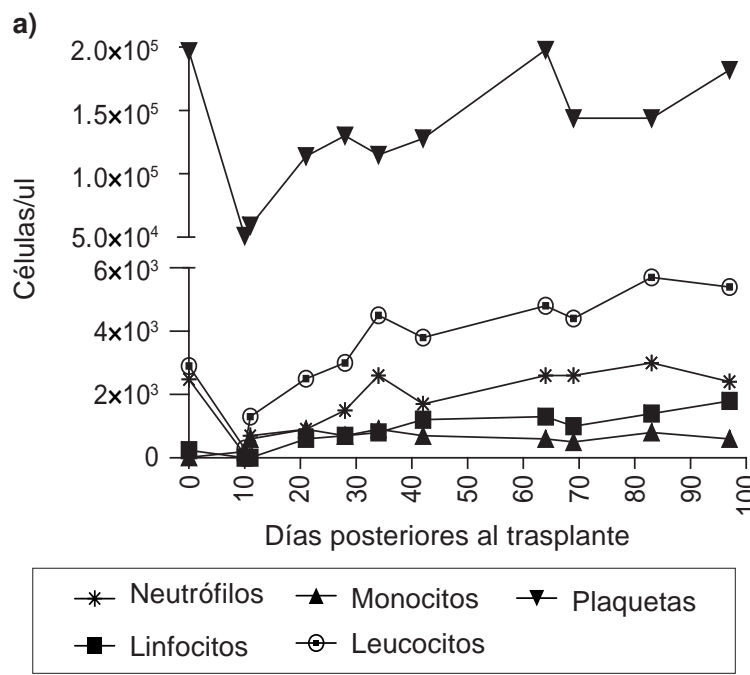

b)

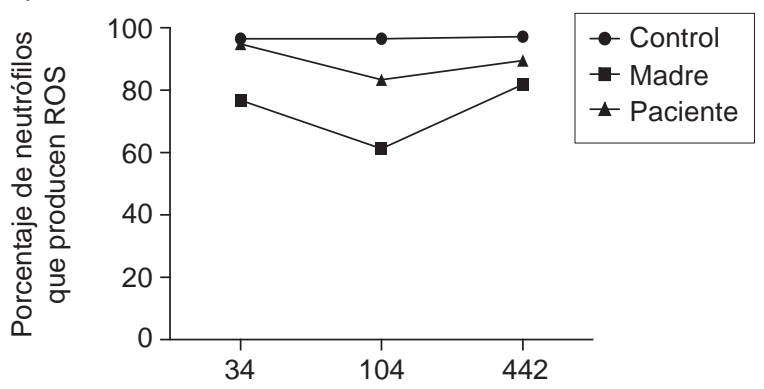

Días posteriores al trasplante

c)

\begin{tabular}{|l|c|c|c|}
\cline { 2 - 4 } \multicolumn{1}{c|}{} & \multicolumn{3}{c|}{ Índice de estimulación } \\
\cline { 2 - 4 } \multicolumn{1}{c|}{} & día +34 & día +104 & día +442 \\
\hline Paciente & 106,1 & 103 & 193,4 \\
\hline Madre & 100,48 & 96,5 & 212,8 \\
\hline Control & 136 & 109 & 212,9 \\
\hline
\end{tabular}

Figura 4. Reconstitución inmunológica posterior al trasplante a) Los datos indican el conteo de leucocitos, neutrófilos, linfocitos, monocitos y plaquetas desde el día 0 hasta el día 97 después del trasplante. b) Se muestra el porcentaje (\%) de neutrófilos que produjeron especies reactivas del oxígeno después de la estimulación con acetato de forbol miristato (PMA). Después del trasplante los neutrófilos del paciente recuperaron la producción de especies reactivas del oxígeno. c) Se muestra el índice de estimulación de los neutrófilos que reaccionaron con el tratamiento con PMA. El índice de estimulación corresponde a la media geométrica de la intensidad media de fluorescencia de las células estimuladas con PMA sobre la media geométrica de la intensidad media de fluorescencia de las células no estimuladas. 
revisten gravedad y están asociadas a complicaciones potencialmente fatales. A pesar de la profilaxis, el paciente comenzó a presentar infecciones desde los siete meses de edad, hasta que finalmente desarrolló meningitis y sepsis a los siete años, lo cual obligó a considerar la posibilidad de un trasplante de células madre hematopoyéticas ante el riesgo creciente de infecciones que amenazaban su vida.

El gen responsable de la enfermedad granulomatosa crónica ligada al cromosoma $\mathrm{X}$ es el $C Y B B$, que se localiza en el brazo corto del cromosoma $X(X p 21.1)$ y está compuesto de 13 exones que codifican para una proteína de transmembrana denominada gp91 ${ }^{\text {phox }}$ (22). Cerca de $70 \%$ de los casos de esta enfermedad se deben a mutaciones en el $C Y B B$ asociadas a la región promotora $(0,7 \%)$, a pequeñas deleciones o inserciones $(2,8 \%)$, a inserciones $(7,9 \%)$, a mutaciones que afectan el procesamiento alternativo $(17,6 \%)$, a deleciones $(35,6 \%)$ y a mutaciones con cambio de sentido o sin este $(35,4 \%)(23)$.

En este caso, el paciente presentaba una deleción que involucraba todo el contexto genómico del CYBB. Aproximadamente, el $10 \%$ de los pacientes con la enfermedad presentan grandes deleciones que afectan uno o más exones del gen, e incluso estas pueden abarcar genes contiguos como el $X K$ (síndrome de McLeod), el OTC (transcarbamilasa de ornitina), el $D M D$ (distrofia muscular de Duchenne) y el $R P$ (retinitis pigmentosa), entre otros $(23,24)$. En el presente estudio no se pudieron establecer los puntos de quiebre 5' y 3' de la deleción, por lo tanto, no fue posible establecer el rango de genes afectados, incluidos los ya mencionados. No obstante, el paciente no presentó manifestaciones clínicas asociadas a ninguno de estos síndromes.

Los tratamientos antimicrobianos profilácticos de la enfermedad granulomatosa crónica incluyen antibióticos, antifúngicos, rhIFN $\gamma$ y esteroides en ciclos cortos, así como el manejo quirúrgico para algunas complicaciones como los abscesos. Sin embargo, estos solo reducen la frecuencia y la gravedad de las enfermedades infecciosas a las que son propensos quienes padecen la enfermedad, y que, indefectiblemente, afectan su calidad de vida e, incluso, causan la muerte (25). De hecho, con el tratamiento médico solo $50 \%$ de los pacientes llegan a los 30 años de edad $(26,27)$.

El trasplante de células madre hematopoyéticas es una opción de tratamiento para los pacientes con enfermedad granulomatosa crónica; sin embargo, no es frecuente recurrir a ella debido a la mortalidad y la morbilidad asociadas al procedimiento (3). El trasplante con un donante haploidéntico aumenta la posibilidad de la falla del injerto y retrasa la reconstitución inmunológica; sin embargo, si hay un donante emparentado con HLA idéntico, la supervivencia del injerto mejora hasta en el $90 \%$ (26). Además, el uso de tratamientos de acondicionamiento como el de intensidad reducida ha logrado disminuir los riegos asociados al trasplante, incluso en aquellos con donantes no emparentados (3).

En un estudio prospectivo realizado por Güngör, et al., se evaluó el efecto de un tratamiento de acondicionamiento de intensidad reducida en 56 pacientes con enfermedad granulomatosa crónica a quienes se les había hecho un trasplante de células madre hematopoyéticas. En 21 de los pacientes el trasplante se hizo con donante emparentado $y$, en 35 , con donante no emparentado, y bajo este esquema solo $5 \%$ de los pacientes presentó una falla del injerto, en tanto que la enfermedad de injerto contra huésped aguda de grado II-IV o de grado III-IV se presentó en 11 y $4 \%$ de los pacientes, respectivamente. Debe anotarse que en todos estos casos se trataba de pacientes a quienes se les había hecho el trasplante con donante no emparentado. Por último, la supervivencia total fue de $93 \%$ a los 21 meses de seguimiento y los autores concluyeron que el tratamiento de acondicionamiento de intensidad reducida era seguro y de baja toxicidad orgánica para los pacientes (28). Por el contrario, los tratamientos de acondicionamiento mieloablativo se han asociado con una toxicidad orgánica grave, particularmente cuando el receptor presenta enfermedad inflamatoria o infección (28). El paciente de este estudio recibió un tratamiento de acondicionamiento de intensidad reducida y no presentó infecciones ni enfermedad de injerto contra huésped o toxicidad orgánica.

El paciente fue diagnosticado en el momento del nacimiento con enfermedad granulomatosa crónica ligada al cromosoma $X$, y solo a los ocho años de edad, después de haber sufrido infecciones graves y recurrentes potencialmente fatales, se consideró el trasplante de células madre hematopoyéticas. En el estudio de Ahlin, et al., se comparó la terapia convencional y el trasplante de células madre hematopoyéticas en un grupo de pacientes con enfermedad granulomatosa crónica, y se encontró que $53 \%$ de aquellos que habían recibido la terapia convencional, murieron como consecuencia de complicaciones de la enfermedad, mientras que $92 \%$ 
de aquellos con la misma enfermedad ligada al cromosoma $\mathrm{X}$ o autosómica recesiva que recibieron trasplante de células madre hematopoyéticas con donantes emparentados y no emparentados, sobrevivieron al procedimiento después de 7,7 años de seguimiento en promedio.

Esto sugiere que no solo los pacientes con formas graves de la enfermedad granulomatosa crónica deben recibir trasplante, sino todos los que padezcan la enfermedad y tengan hermanos con un sistema HLA idéntico o donantes compatibles no emparentados. Esta opción de tratamiento debe ofrecerse lo más pronto posible, antes de que se presenten infecciones graves, enfermedad inflamatoria u otras complicaciones potencialmente fatales (29). Asimismo, los pacientes con esta enfermedad que reciben un trasplante de células madre hematopoyéticas tienen una calidad de vida comparable a la reportada en niños sanos, mientras que los que reciben tratamiento convencional presentan menor calidad de vida (27).

A pesar del retraso del trasplante en el caso de este paciente, hoy, a los tres años del procedimiento, su condición general es buena y ha recuperado completamente la función inmunitaria. Su última DHR 123 en el día 442 después del trasplante, demostró que más del $89 \%$ de las células (figura 4b) producían especies reactivas del oxígeno en niveles comparables a los de individuos sanos. En la enfermedad granulomatosa crónica no se considera necesario el quimerismo completo del sistema hematopoyético en el receptor para mejorar la condición clínica. Hay evidencia que sugiere que, aproximadamente, con $10 \%$ de los neutrófilos normales hay mejoría significativa de la enfermedad y un efecto positivo en la supervivencia $(21,30)$. A lo largo de este estudio se hicieron varias pruebas de DHR 123 para determinar el estado del quimerismo del paciente, cuyos resultados cuantitativos, como lo demostraron Kim, et al., se correlacionan con el estado del quimerismo observado en los análisis de la PCR de repeticiones cortas en tándem (21).

Por último, los pacientes con enfermedad granulomatosa crónica son propensos a contraer un amplio espectro de infecciones bacterianas y fúngicas potencialmente fatales desde edades muy tempranas, y dado que las manifestaciones clínicas son muy variadas, es difícil clasificar el riesgo de infecciones o mortalidad en un paciente determinado. Aunque la profilaxis antimicrobiana disminuye el riesgo de infecciones, es necesario considerar el trasplante de células madre hematopoyéticas como una alternativa viable que puede curar la enfermedad, con el fin de disminuir las tasas de morbimortalidad asociadas a esta enfermedad.

\section{Agradecimientos}

Los autores agradecen a Claudia Trujillo por la revisión crítica del manuscrito.

\section{Conflicto de intereses}

Los autores de este artículo manifestamos que no tenemos conflicto de intereses con respecto a la información aquí suministrada.

\section{Financiación}

Este trabajo fue financiado por el Departamento Administrativo de Ciencia, Tecnología e Innovación, Colciencias (Proyecto 111554531412) y por la Universidad de Antioquia.

\section{Referencias}

1. Seger RA. Chronic granulomatous disease: Recent advances in pathophysiology and treatment. Neth $\mathrm{J}$ Med. 2010;68:334-40

2. Rosenzweig SD. Chronic granulomatous disease: Complications and management. Expert Rev Clin Immunol. 2009;5:45-53. http://dx.doi.org/10.1586/1744666X.5.1.45

3. Kang EM, Marciano BE, DeRavin S, Zarember KA, Holland SM, Malech HL. Chronic granulomatous disease: Overview and hematopoietic stem cell transplantation. J Allergy Clin Immunol. 2011;127:1319-26. http://dx.doi. org/10.1016/j.jaci.2011.03.028

4. Notarangelo LD. The long road to optimal management for chronic granulomatous disease. J Allergy Clin Immunol. 2013;132:1164-5. http://dx.doi.org/10.1016/j.jaci.2013.08.035

5. Holland SM. Chronic granulomatous disease. Hematol Oncol Clin North Am. 2013;27:89-99. http://dx.doi.org/10. 1016/j.hoc.2012.11.002

6. Segal $\mathbf{B H}$, Veys $\mathbf{P}$, Malech $\mathbf{H}$, Cowan MJ. Chronic granulomatous disease: Lessons from a rare disorder. Biol Blood Marrow Transplant. 2011;17:S123-31. http://dx.doi. org/10.1016/j.bbmt.2010.09.008

7. Agudelo-Flórez P, Prando-Andrade CC, López JA, CostaCarvalho BT, Quezada A, Espinosa FJ, et al. Chronic granulomatous disease in Latin American patients: Clinical spectrum and molecular genetics. Pediatr Blood Cancer. 2006;46:243-52. http://dx.doi.org/ 10.1002/pbc.20455

8. Parikh SH, Szabolcs P, Prasad VK, Lakshminarayanan $\mathrm{S}$, Martin PL, Driscoll TA, et al. Correction of chronic granulomatous disease after second unrelated-donor umbilical cord blood transplantation. Pediatr Blood Cancer. 2007;49:982-4. http://dx.doi.org/10.1002/pbc.21365

9. Seger RA, Gungor T, Belohradsky BH, Blanche S, Bordigoni P, Di Bartolomeo P, et al. Treatment of chronic granulomatous disease with myeloablative conditioning and an unmodified hemopoietic allograft: A survey of the European experience, 1985-2000. Blood. 2002;100:434450. http://dx.doi.org/10.1182/blood-2002-02-0583 
10. Kuhns DB, Alvord WG, Heller T, Feld JJ, Pike KM, Marciano $\mathrm{BE}$, et al. Residual NADPH oxidase and survival in chronic granulomatous disease. N Engl J Med. 2010;363:2600-10. http://dx.doi.org/10.1056/NEJMoa1007097

11. Gatti RA, Meuwissen HJ, Allen HD, Hong R, Good RA. Immunolo gical reconstitution of sex-linked lymphopenic immunological deficiency. Lancet. 1968;2:1366-9. http://dx. doi.org/10.1016/S0140-6736(68)92673-1

12. Bach FH, Albertini RJ, Joo P, Anderson JL, Bortin MM. Bone-marrow transplantation in a patient with the WiskottAldrich syndrome. Lancet. 1968;21364-6. http://dx.doi. org/10.1016/S0140-6736(68)92672-X

13. Cant A, Slatter M, Battersby A. Advances in management of primary immunodeficiency. Paediatr Child Health. 2013: 115-20. http://dx.doi.org/10.1016/j.paed.2013.02.001

14. Filipovich A. Hematopoietic cell transplantation for correction of primary immunodeficiencies. Bone Marrow Transplant. 2008;42:S49-52. http://dx.doi.org/10.1038/bmt.2008.121

15. Slatter MA, Cant AJ. Hematopoietic stem cell transplantation for primary immunodeficiency diseases. Ann N Y Acad Sci. 2011;1238:122-31. http://dx.doi.org/10.1111/ j.1749-6632. 2011.06243.x

16. Goussetis E, Konialis CP, Peristeri I, Kitra V, Dimopoulou M, Petropoulou T, et al. Successful hematopoietic stem cell transplantation in 2 children with X-linked chronic granulomatous disease from their unaffected HLAidentical siblings selected using preimplantation genetic diagnosis combined with HLA typing. Biol Blood Marrow Transplant. 2010;16:344-9. http://dx.doi.org/10.1016/j.bbmt. 2009.10.010

17. Agudelo-Flórez P, Navarro S, Luttges P, López JA, Norambuena X, Navarrete SC, et al. Report of a new mutation in CYBB gene in two patients with $\mathrm{X}$ linked chronic granulomatous disease. Rev Med Chil. 2006;134:965-72. http://dx.doi.org/S0034-98872006000800004

18. López JA, Vélez G, Mendivil M. Caracterización clínica y genético-molecular de un paciente con enfermedad granulomatosa crónica ligada al X. Reporte de una nueva mutación asociada al splicing. Caso clínico. Rev Chil Pediatr. 2014;85:213-21. http://dx.doi.org/10.4067/S037041062014000200012

19. Rojas-Restrepo J, Álvarez-Álvarez J, Montoya-Giraldo J, Trujillo-Vargas C. Validación de la técnica de dihidrorodamina 123 para el diagnóstico de la enfermedad granulomatosa crónica en Colombia. Inmunología. 2014;33:71-80. http:// dx.doi.org/10.1016/j.inmuno.2014.03.001

20. Agudelo-Flórez P, López JA, Redher J, CarneiroSampaio MM, Costa-Carvalho BT, Grumach AS, et al. The use of reverse transcription-PCR for the diagnosis of X-linked chronic granulomatous disease. Braz J Med Biol Res. 2004;37:625-34. http://dx.doi.org/10.1590/S0100$879 \times 2004000500001$
21. Kim HY, Kim HJ, Ki CS, Kim DW, Yoo KH, Kang ES. Rapid determination of chimerism status using dihydrorhodamine assay in a patient with $\mathrm{X}$-linked chronic granulomatous disease following hematopoietic stem cell transplantation. Ann Lab Med. 2013;33:288-92. http://dx.doi.org/10.3343/ alm.2013.33.4.288

22. Jirapongsananuruk $\mathrm{O}$, Niemela JE, Malech HL, Fleisher TA. CYBB mutation analysis in X-linked chronic granulomatous disease. Clin Immunol. 2002;104:73-6. http://dx.doi. org/10.1006/clim.2002.5230

23. Roos D, Kuhns DB, Maddalena A, Roesler J, López JA, Ariga $\mathrm{T}$, et al. Hematologically important mutations: X-linked chronic granulomatous disease (third update). Blood Cells Mol Dis. 2010;45:246-65. http://dx.doi.org/10.1016/j.bcmd. 2010.07.012

24. Arai T, Oh-ishi T, Yamamoto H, Nunoi H, Kamizono $\mathrm{J}$, Uehara $\mathbf{M}$, et al. Copy number variations due to large genomic deletion in X-linked chronic granulomatous disease. PloS One. 2012;7:e27782. http://dx.doi.org/10. 1371/journal.pone.0027782

25. van den Berg JM, van Koppen E, Ahlin A, Belohradsky BH, Bernatowska E, Corbeel L, et al. Chronic granulomatous disease: The European experience. PloS One. 2009;4: e5234. http://dx.doi.org/10.1371/journal.pone.0005234

26. Gozdzik J, Pituch-Noworolska A, Skoczen S, Czogala $\mathrm{W}$, Wedrychowicz A, Baran $\mathrm{J}$, et al. Allogeneic haematopoietic stem cell transplantation as therapy for chronic granulomatous disease--single centre experience. J Clin Immunol. 2011;31:332-7. http://dx.doi.org/10.1007/ s10875-011-9513-y

27. Cole T, McKendrick F, Titman P, Cant AJ, Pearce MS, Cale CM, et al. Health related quality of life and emotional health in children with chronic granulomatous disease: A comparison of those managed conservatively with those that have undergone haematopoietic stem cell transplant. J Clin Immunol. 2013;33:8-13. http://dx.doi.org/10.1007/ s10875-012-9758-0

28. Gungor T, Teira P, Slatter M, Stussi G, Stepensky P, Moshous D, et al. Reduced-intensity conditioning and HLA-matched haemopoietic stem-cell transplantation in patients with chronic granulomatous disease: A prospective multicentre study. Lancet. 2014;383:436-48. http://dx.doi. org/10.1016/S0140-6736(13)62069-3

29. Ahlin A, Fugelang J, de Boer M, Ringden O, Fasth A, Winiarski J. Chronic granulomatous disease-haematopoietic stem cell transplantation versus conventional treatment. Acta Paediatr. 2013;102:1087-94. http://dx.doi.org/10.1111/ apa.12384

30. Abraham RS. Relevance of laboratory testing for the diagnosis of primary immunodeficiencies: A review of casebased examples of selected immunodeficiencies. Clin Mol Allergy. $2011 ; 9: 6$. http://dx.doi.org/10.1186/1476-7961-9 